\title{
Ethnographic and Case Study Approaches: Philosophical and Methodological Analysis
}

\author{
Lusia Neti Harwati* \\ Faculty of Cultural Sciences, Brawijaya University, Indonesia \\ Corresponding author: Lusia Neti Harwati, E-mail: lusianeti@ub.ac.id
}

\begin{tabular}{l} 
ARTICLE INFO \\
\hline Article history \\
Received: January 16, 2019 \\
Accepted: April 27, 2019 \\
Published: April 30, 2019 \\
Volume: 7 Issue: 2
\end{tabular}

Conflicts of interest: None Funding: None

\begin{abstract}
In qualitative methods, there are various approaches that can be used to answer particular social questions, for example ethnography and case study. Two studies conducted by different researchers in China and Australia using these approaches were described and analysed in order to find out their similarities and differences in terms of philosophical and methodological perspectives, in the hope that it will provide an insightful contribution to a critical review of ethnography and case study reports. It is found that the ethnograpic study in China was clasiffied in ethnographic fieldwork, whereas the case study conducted in Australia was categorised in explanatory, multi-cases study. Furthermore, these two studies produced different knowledge within the field of education. The first study revealed that basic education were related to literacy, numeracy, and cultural characteristics of China, whereas the study conducted in Australia offered statistical data that can be used to explain minority languages maintenance program in Wollongong-Shellharbour. In relation to their methodoligal practices, however, focus group discussion and interview conducted in Zhejiang Province, China produced irrelevant data and those had been held in Wollongong, Australia, had limited participants.
\end{abstract}

Key words: Qualitative, Ethnography, Case Study, Philosophy, Methodology

\section{INTRODUCTION}

In social sciences research, qualitative methods are used to answer particular social questions, such as why does a particular reality experienced by participants. These methods primarily focus on finding out why human beings act, think or feel the way they do in their natural setting. They also can refer to research about organizational functioning and social movements (Daniel, 2016; Mohajan, 2018). There are several approaches have been introduced and used in qualitative research which are believed can produce different result of study, such as grounded theory, ethnography, discourse analysis, document analysis, Participatory Action Research (PAR), case study, and many others. However, not all the approaches mentioned will be discussed but ethnography and case study. It is based on the reason that the main purpose of this paper is to compare and contrast two studies using ethnographic and case study approaches. Their philosophical and methodological similarities and differences will be discussed. How do these two approaches produce different knowledge within the field of education will be analysed. Critique of the two studies also will be offered. Ethnography and case study are chosen to be compared because they are two of the most popular approaches in qualitative methods (Suryani, 2008). In addition, both approaches have a similar theoretical framework. Case study tends to follow the characteristics of ethnography in terms of reality observation.
More specifically, a study conducted in Zhejiang Province, China and another from Wollongong, Australia have been selected to be reviewed. The reason behind this selection is based on the argument that both countries have cultural differences. "China is a collective society and Australia is an individualistic society" (Chung \& Ingleby, 2011, p. 175). This statement implies that Chinese people, including participants of the study in Zhejiang Province believe that maintaining social relationships is very essential and they tend to have a more dependent relationship with each other. In the study conducted in Australia, on the other hand, German and Macedonian communities living in Wollongong, as participants, cannot be categorized in an individualistic society. They are motivated to preserve their mother tongue as a local identity as well as one of minority languages in Australia as a dominant culture. Using mother tongue to communicate with other members of the communities is vital. Living in harmony and dependent relationship are considered as their way of life. It can be concluded, therefore, that participants of both studies have similar values of life.

Before we go on to the discussion about the similarities and differences of those two studies, their summaries will be presented below. It is important to comprehend what kinds of studies conducted by the researchers, why do they choose ethnographic and case study approaches and what are the results of their studies. The definition, purpose and 
characteristics of both ethnography and case study then will be explained briefly.

\section{THE SUMMARIES OF THE TWO STUDIES}

\section{Understanding Basic Education Policies in China}

\section{An Ethnographic Approach}

\section{By Kai-Ming Cheng}

Understanding Basic Education Policies in China is a study of educational policies conducted by Kai-Ming Cheng in Zhejiang Province. Basic education is chosen because it has become increasingly a local endeavour than any other levels of education in China after the government implemented the financial reforms in the mid-1980s.

The main purpose of this study is to answer two questions: (1) What do students gain from basic education? and (2) How is basic education provided? These two research questions also can be paraphrased as follows: Are basic educational needs being met? and How are these basic educational needs met or not met? An ethnographic approach is used due to the reason that education is a process. In order to understand this process, the researcher needs to comprehend the contexts in which this process takes place. In addition, both quantitative and qualitative research methods (mix methods) are implemented in order to gain a more realistic overview of basic educational policies in China.

Unstructured interviews and questionnaires are chosen as instruments of data collection with a small sample of parents, teachers, principals, and local leaders. Furthermore, a focus group discussion/interview is held with a Neighbourhood Committee. The members are elected from the families who live in the neighbourhood comprising one street. This group discussion is essential to comprehend what are perceived as basic educational needs.

Overall, this study offers some comprehensive empirical evidence of how basic educational practices are carried out in China and how they are connected with the cultural characteristics of China. Basic education is not only related to literacy and numeracy but also to moral and relation to other people in the society (social relationships).

\section{An Empirical Case Study: German and Macedonian Language Maintenance in Wollongong}

\section{By Mary Kalantzis, Bill Cope and Diana Slade}

An Empirical Case Study: German and Macedonian Language Maintenance in Wollongong is a study of minority languages (German and Macedonian) maintenance conducted by Mary Kalantzis, Bill Cope and Diana Slade. Adults and children with German and Macedonian languages background are surveyed in a number of local settings in the Wollongong-Shellharbour region, chosen because they show significant statistical variation of socio-economic level. The main objectives of this study is to obtain authoritative data on the differing attitudes to preserve of the native language held by Macedonian and German communities in Wollongong and to assess how this is linked to proficiency in English.
An empirical case study is used because the researchers need to gather enough information about the German and Macedonian groups. This information permits them to effectively understand opinions and attitudes differences of these two groups in the attempt to maintain their mother tongue.

One of methods of data collection of this study is structured interviews with purposive sampling of targeted categories: employed/unemployed; old/young; recent arrival/ long settled; low/high education level; male/female. Questionnaires to both children and their parents are also issued. In addition, discussion/interview groups: German language background and Macedonian language background are held.

This study offers some statistical data of how many people (adults and children) with German and Macedonian languages background motivate to maintain their mother tongue and which language is the children more familiar with. Both German and Macedonian adults are more motivated to preserve and learn their mother tongue than children. They believe that both reading and speaking using their native languages are important (Macedonian adults 87.8 per cent; German adults 88.3 per cent but only 60 per cent of Macedonian children and 47.4 per cent of German children). Furthermore, when adults are asked which languages their children speak, more Germans say that their children speak English only than do Macedonians (Germans 28.3 per cent; Macedonians 6.1 per cent).

\section{ETHNOGRAPHY AND CASE STUDY}

\section{Definition, Purpose, and Characteristics}

\section{Ethnography}

Ethnographic approach is related to study about relationships between people and several aspects of their life, such as socio-political, culture and history. The main purpose of the ethnographic approach in social sciences is to understand the relationship between people and their social environment (Hallet \& Barber, 2014). The characteristic of this approach is close relationship between researcher and the researched. Case Study

Case study is an approach, which involves studying individual cases in their real life context for a long period of time. The case studied can be culture, society, community, organization or phenomenon, such as beliefs, practices or interactions (Harrison, Birks, Franklin, \& Milles, 2017). The purpose of case study varies, depending on its type.

There are several types of case study. Yin (2003) states that this approach can be based on single or multiple case studies. Whether single or multiple, it can be exploratory, explanatory or descriptive. A single-case study emphasizes on a single case only, whereas multiple-case studies include two or more cases in the same study. An exploratory case study attempts to define questions and hypotheses of a subsequent study, while an explanatory case study tries to explain how particular phenomena happened. Here, data are presented, bearing on cause-effect relationships. A descriptive case study depicts a phenomenon completely within its context (ibid). Respondents are seen as experts not just as 
objects that inform or produce data and this approach studies a typical case, using a number of methods to prevent errors and distortions.

\section{Philosophical and Methodological Perspectives}

We now have insights into the definition, purpose and characteristics of both the ethnographic and case study approaches. How about their similarities and differences in terms of philosophical and methodological perspectives? Detailed explanation about this will be presented below.

\section{Ethnographic approach}

\section{Philosophical Perspective}

In order to understand philosophical perspective of the ethnographic approach, three dominant perspectives in social sciences will be outlined. It is important to note that the philosophical perspective of the ethnographic approach cannot be separated from one of those three dominant perspectives. There are three dominant perspectives in the social sciences, namely the positivist perspective, the interpretive perspective and the critical perspective, which have different perception of reality. Positivists argue that reality is everything can be seen through the senses. It is 'out there', objective and governed by natural and fixed law (Shakouri, 2014). By contrast, interpretive theorists maintain that reality is 'not out there' and can be found in the minds of human beings. Reality is objective, constructed by social interaction and internally experienced by members of society (Sarantakos, 2013).

Furthermore, interpretive perspective "is concerned with the emphatic understanding of human action rather than with the forces that deemed to act on it" (Bryman, 2004). It means that the emphasis of interpretive perspective is not on the explanation of people behaviour, but rather on understanding of their behaviour.

"Identification and understanding" are the emphasis of the critical perspective (Dent, Khin, \& Ismail, 2013). More specifically, this perspective has different view about reality. Critical theorists believe that reality is created by human beings, not by nature. There are powerful people who manipulate and persuade others to accept things and interpret them based on their own perspective.

Among those three dominant perspectives, the ethnographic approach adopts the second one that is interpretive perspective. It is mentioned earlier that the main objective of the ethnographic approach in social sciences is to comprehend the relationship between people and their social environment. However, understanding 'surface relationship' is not its emphasis. Instead, the ethnographic approach wants to go beyond this. It attempts to reveal reality, for instance what people's opinions are about a particular phenomenon occurred in their social context and what their action is. It is similar with the emphasis of interpretive perspective, which is understanding human behaviour. The ethnographic implements holism approach and in-depth studies. The former means that the ethnographic approach perceives people's action in the context of the whole system while the latter refers to the ethnographer's interest to rely on information obtained by involving in daily lives of the groups being investigated and experiencing culture the way these groups do.

\section{Methodological Perspective}

Participant observation is considered as a central method of the ethnographic approach. It is often combined with other methods especially informal or unstructured interview. Participant observation means that ethnographer becomes part of the situation being studied in order to be able to feel the way people do in that situation. It is essential therefore, for the ethnographer to be actively involved in the respondents' daily lives. This method enables the ethnographer to depict what goes on, where and when a particular social phenomenon occurs, what and who are involved, how and why it happens (Gobo, 2011). In other words, participant observation can help the ethnographer to reveal reality behind the phenomenon happened in a social environment.

Study of documents, for instance a life history is different. According to Rahamah, Bakar, and Abdullah (2008), the life history is the autobiography of a person that can be gained via interview and guided conversation. This technique, therefore, enables the ethnographer to obtain insights into the respondents' world-view and social relationships.

\section{Case study approach}

\section{Philosophical Perspective}

Some theorists believe that case study approach is a method in logical positivist tradition (Yin, 2003). This belief is based on the reason that this approach "can be conducted through the collection and analysis of empirical data" (Yin, 2003 , p. 163). These data then are used to present findings and conclusions. However, if we trace back on the types of case study: whether single or multiple, case study can be exploratory, explanatory or descriptive, it will be clear that this approach also adopts interpretive perspective. Basically, these three types of case study focus on the social phenomenon. Case study tries to find out what kind of phenomenon exists, then explain how it occurred by describing it completely. In the attempt to explore, explain and describe this phenomenon, the researcher needs to understand about point of view of people who experienced it since reality only can be found in their minds, which is similar with the perception of interpretive perspective.

Moreover, case study also stresses the holistic examination of the phenomenon or the issue (Harrison, Birks, Franklin, \& Milles, 2017). In other words, holism approach is applied. It means that it tries to analyse a particular case and bring it into wider category of cases. The researcher then relates it to other cases that have similar characteristics.

\section{Methodological Perspective}

The common methods used in the case study approach are life histories, document, in-depth interviews and participant observation. It can be seen that case study uses the same methods of data collection with the ethnographic approach but in-depth interviews. This method therefore, will be outlined below. There are many types of interviews. Two examples of these types are structured and unstructured interviews. Structured interview refers to the interview, which has a strict procedure and schedule. Content, wording, order 
of the questions and other elements of the interview are unchangeable. Unstructured interview is a type of interview, which has no strict schedule to follow and its structure is flexible (Buriro, Awan, \& Lanjwani, 2017). The in depth-interview commonly used in the case study approach is one form of unstructured interview. The in-depth interview provides more freedom for the interviewer to present the questions, in order to meet the goals of the study.

The explanation about philosophical and methodological perspectives of both the ethnographic and case study approaches can be summarised as follows:

\begin{tabular}{|c|c|}
\hline Ethnographic Approach & Case Study Approach \\
\hline Philosophical Perspective & Philosophical \\
\hline Interpretive & Perspective \\
\hline Holism & Interpretive \\
\hline In-depth studies & Holism \\
\hline \multicolumn{2}{|l|}{ Methodological Perspective } \\
\hline Ethnographic fieldwork: & Methodological \\
\hline Interview, participant & Perspective \\
\hline observation & Life histories, document, \\
\hline Ethno-historic research: & in-depth \\
\hline $\begin{array}{l}\text { Documents, such as life } \\
\text { histories, diaries, personal } \\
\text { letters }\end{array}$ & $\begin{array}{l}\text { Interviews, participant } \\
\text { observation }\end{array}$ \\
\hline
\end{tabular}

\section{Analysis of the Two Studies}

\section{Philosophical perspective}

\section{Similarities}

Both studies conducted in China and Australia implement interpretive perspective and holism approach. In the first study, Understanding basic Education in China: An Ethnographic Approach for example, Kai-Ming Cheng as the researcher proposes two research questions: (1) What do students gain from basic education? and (2) How is basic educational provided? In other words, he attempts to reveal reality in the minds of the respondents who internally experience it. The word 'reality' here refers to 'basic education'. Kai-Ming Cheng wants to go beyond this. He tries to help the respondents to understand and interpret what they perceive of basic education is. It is similar with the perception of reality of the interpretive perspective that reality can be found in the minds of people.

Similarly, in the second study, An Empirical Case Study: German and Macedonian Language Maintenance in Wollongong, Mary Kalantzis, Bill Cope and Diana Slade want to reveal reality by proposing the research question: How do German and Macedonian communities preserve their mother tongue? Here, the researchers try to comprehend and interpret what the respondents' think about the importance of minority languages maintenance in dominant culture and what their actions to preserve their mother tongue are.

Holism approach is also applied to the two studies. Although Kai-Ming Cheng conducts his study in Zhejiang Province, it does not mean that he only wants to interpret the respondents' opinions about basic education in their region. Instead, he tries to relate these opinions to larger social context: China. In the second study, the researchers attempt to examine holistically a social phenomenon happened in
Wollongong-Shellharbour. They seek to avoid the separation of German and Macedonian communities from the larger context to which they may be related: minority communities in a dominant culture that is Australia. It is based on the reason that case studies focus more on the holistic examination of a phenomenon or an issue. Wollongong-Shellharbour are chosen because statistically, socio-economic level in these regions vary.

\section{Differences}

The researchers of both studies perceive that the respondents hold a central position. It is based on the interpretive theorists' perception of human being: they occupy a central position and create reality. Basic education policies in China and minority languages maintenance in Australia therefore, only can be interpreted by understanding the respondents' point of view. However, there is a difference in applying this perspective. In order to comprehend the basic education policies in China, Kai-Ming Cheng uses a wider sampling: parents, teachers, principles, and local leaders. It means that he tries to obtain variety of opinions about basic education not only from the students' point of view, but also from the stakeholder.

By contrast, in the attempt to understand what do people do to maintain the minority languages, Mary Kalantzis, Bill Cope and Diana Slade simply interpret the opinions of German and Macedonian communities. They do not try to obtain different point of views from the community of the dominant culture: the Australians.

\section{Methodological perspective}

\section{Similarities}

The study of basic education policies in China can be categorised in ethnographic fieldwork whereas the second one, the empirical case study conducted in Australia is classified in explanatory, multi-cases study. There are two reasons why this study can be classified in explanatory, multi-cases study. The first one is that the empirical case study in Wollongong tries to explain several factors influence German and Macedonian communities' opinions about the importance of native languages maintenance. It means that the researchers try to explain "cause-effect relationships" (Yin, 2003, p. 5). Furthermore, there are two cases included in this study: what do people of German language background and those of Macedonian language background think about the importance of minority languages preservation.

One of similarities of both studies is that they use interview as method of data collection. The ethnographic study in China which is named as ethnographic fieldwork chooses interview to gather data, conducted while the researcher is living with the respondents in Zhejiang Province. Likewise, interview is also used as method of data collection in the empirical case study of minority languages maintenance in Wollongong, Australia. In addition, questionnaires are also issued. In the ethnographic study in China, parents, teachers, principles, and local leaders are chosen as sample. This method of data collection is used in order to understand why schooling (Cheng, 2000). Questionnaires in the case study conducted in Wollongong, Australia are addressed to both children and 
their parents (Kalantzis, Cope \& Slade, 1989). The parents are evaluated objectively in language proficiency.

The other similarity is that both studies use focus group discussion/interview. According to Mishra (2016), focus group discussion/interview is an in-depth interview designed for small groups. Here, a particular topic of interest or relevance to the participants and the researcher is addressed. In the ethnographic study conducted in China, focus group discussion/interview is held with a Neighbourhood Committee. The members are elected from the families who live in the same neighbourhood. This group discussion is vital to understand what are perceived as basic educational needs (Cheng, 2000). In the empirical case study conducted in Australia, two focus group interviews/discussions: German language background and Macedonian language background are held. These discussions are essential to comprehend the value of maintaining native languages (Kalantzis, Cope \& Slade, 1989).

Differences

In terms of methodological perspective, there is no significant difference between the two studies but number of participants in the group discussions/interviews. In the ethnographic study conducted in China, the number of participants is limited. Eight members (all are parents) are present, elected from a particular neighbourhood.

In the empirical case study conducted in Australia, the number of participants in the German and Macedonian group discussions is greater, coming from more diverse sources, for example, church organizers, university students, welfare workers, teachers and parents. Broadly speaking, for complex problems focus group discussion should be kept to limited number of participant, usually 10 to 12 people with similar backgrounds (Mishra, 2016). However, it does not mean that research problems of the study conducted in China are more complex than those of the study in Australia.

The number of participants of focus group discussions/ interviews in the empirical case study in Australia is greater because the researchers want to understand opinions about the importance of the mother tongue maintenance both from German and Macedonian languages background. The discussions therefore, are divided into two groups: (1) German language background and (2) Macedonian language background.

\section{How do these two approaches produce different knowledge?}

Although the two approaches (ethnographic and case study) being analysed have the similar philosophical and methodological perspectives, they produce different knowledge. It is based on the fact that their purposes are different. The main purpose of the ethnographic approach is to describe the culture and life style of the respondents. It means that seeking causes and explanations are not its idea. By contrast, the main objective of the case study approach is to explain a particular phenomenon, such as a project or program, which is "not readily distinguishable from its context" (Yin, 2003, p. 4).

Based on these difference purposes, the two studies being examined also produce different knowledge. The ethnographic study conducted in China, for instance, concludes that basic education is not only related to literacy and numeracy, as commonly mentioned in the literature on schooling but also to the cultural characteristics of China: "good adaptability" and "good human relations" (Cheng, 2000p. 35). It means that in the minds of the respondents, there are educational goals beyond literacy and numeracy. The researcher attempts to comprehend and interpret the respondents' opinions about basic education in relation to values in their culture. This attempt therefore, is more to depict the culture and life style of the respondents rather than to explain why they have such opinions.

It is mentioned earlier that the empirical case study conducted in Australia offers two main results: (1) both German and Macedonian adults are more motivated to preserve and learn their mother tongue than children. They believe that both reading and speaking using their native languages are important (Macedonian adults 87.8 per cent; German adults 88.3 per cent but only 60 per cent of Macedonian children and 47.4 per cent of German children). (2) Germans say that their children speak English only than do Macedonians (Germans 28.3 per cent; Macedonians 6.1 per cent). These statistics are used to explain the particular phenomenon happened in Wollongong-Shellharbour region: the German and Macedonian language maintenance program. This program cannot be separated from the Department of Immigration and Ethnic Affairs" purposes "in commissioning research into the maintenance of languages other than English in Australia" (Kalantzis, Cope, \& Slade, 1989, p. 132).

Furthermore, such statistics data help the researchers to explain why and how languages other than English should be maintained in Australia. It means that the researchers do not separate elements (German and Macedonian languages preservation) from the larger context (other minority languages in Australia) to which they may be related.

On the basis of the explanation made so far, it can be concluded that different approaches produce different knowledge. In addition, the choice of approaches is not based on the preference of the researchers. Instead, it is based on the purpose and topic of the study.

\section{Critique of the two studies}

Although both studies offer the results and data convincingly, it is possible to criticize them. Such criticisms reflected a basic dissatisfaction, related to their methodological practices (focus group discussion/interview) and the choice of the participants. It is mentioned earlier that both studies use focus group discussion/interview as one of methods of data collection. This method is flexible and permits considerable probing. In addition, it enables the researcher to have closer relationship with the participants. However, there is a crucial problem with this method. It is possible that focus groups discussion/interview produce irrelevant data. At this stage, explorative interviews can be used to find the relevant dimensions to ask for and minimize irrelevant data that do not fit with the hypotheses (Caillaud \& Flick, 2017). This problem can be found in the focus group discussion/ interview of the study conducted in China. When the researcher poses a question: "What are the characteristics of a person who cannot survive in this society?" the responses 
converged on two points: "good adaptability" and "good human relations". No one mention literacy and numeracy, which have been his anticipated answers (Cheng, 2000, p. 35). Moreover, when the researcher asks questions related to literacy and numeracy, such as "Don't you think a young person should be able to read a road sign?" the participants do not aware that it is part of formal education because their answer is: "They can always ask for help from passers-by" (Cheng, 2000, p. 35). Based on the example given, it is clear that this focus group discussion/interview produce irrelevant data.

The problem of two focus group discussions/interviews of the study conducted in Australia is related to the choice of the participants. In the attempt to comprehend what do people do to maintain the minority languages, the researchers simply interpret the opinions of German and Macedonian communities (Kalantzis, Cope, \& Slade, 1989). They do not try to obtain different point of views from the community of the dominant culture: the Australians. It would be better if the Australians were involved in this discussion. It is vital to understand different point of views both from the minority and dominant languages communities. However, the two studies examined here present findings, which are useful to obtain understanding of: (1) basic educational practises in China and how these practices are related to cultural characteristics in China (2) minority languages maintenance in the dominant culture.

\section{CONCLUSION}

There are several approaches commonly used in qualitative research which are considered can produce different result of study. Ethnography and case study are two examples of these approaches. There are similarities and differences of both approaches, in terms of philosophical and methodological perspectives.

The study of basic education policies conducted in Zhejiang Province, China is the example of the ethnographic approach, whereas the example of the case study approach can be seen in the study of minority languages maintenance in Wollongong, Australia. The ethnographic study in China can be classified in ethnographic fieldwork and the case study conducted in Australia is categorised in explanatory, multi-cases study. These two studies produce different knowledge within the field of education. It is due to the fact that their purposes are different. The first study offers finding that basic education is not only related to literacy and numeracy but also to cultural characteristics of China. The study in Australia offers statistical data, which are used to explain the particular phenomenon occurred in Wollongong-Shellharbour: minority languages (German and Macedonian) maintenance program.

Although these two studies successfully present useful findings, a number of critiques can be addressed. These critiques are related to their methodological practices (focus group discussion/interview) and the choice of the participants. Focus group discussion/interview conducted in Zhejiang Province, China produce irrelevant data and those held in Wollongong, Australia have limited participants.

\section{REFERENCES}

Burino, A. G., Awan, J. H., \& Lanjwani, A. R. (2017). Interview: A Research Instrument for Social Science Researchers. International Journal of Social Sciences, Humanities, and Education, 1(4) 1-14.

Bryman, A. (2004). Social Research Methods. $2^{\text {nd }}$ Edition. Oxford University Press.

Caillaud, S. \& Flick, U. (2017). Focus groups in triangulation contexts. In R. Barbour \& D. Morgan (Eds.). Advances in Focus Groups Research (pp. 155-177). Hampshire (UK): Palgrave Macmillan.

Cheng, K. M. (2000). Understanding Basic Education Policies in China: An Ethnographic Approach. In Judith Liu, Heidi A. Ross \& Donald P. Kelly (Eds.)., The Ethnographic Eye (pp. 34-36), New York: Falmer Press,

Chung, M \& Ingleby, R. (2011). Overcoming the Cultural Challenges in Supervising Chinese Research Students in Australia. In China's Higher Education Reform and Internationalisation (pp. 17-192), England: Routledge, Abingdon.

Daniel, E. (2016). The Usefulness of Qualitative and Quantitative Approaches and Methods in Reseaching Problem-Solving Ability in Science Education Curriculum. Journal of Education and Practice, 7(15) 91-100.

Dent, M., Khin, E.W.S., \& Ismail, M.N. (2013). Critical and Interpretive Social Science Theory: A Case Study Approach. Actual Problems of Economics, 8(146) 268-275.

Gobo, G. (2011). Ethnographic Methods. Retrieved 27 April 2019, from https://air.unimi.it.

Hallet, R.E \& Barber, K. (2014). Ethnographic Research in a Cyber Era. Journal of Contemporary Ethnography, 43(3) 306-330.

Harrison, H, Birks, M, Franklin, R \& Mills, J. (2017). Case Study Research: Foundations and Methodological Orientations. Forum: Qualitative Social Research Sozial Forchung, 18(1) Art. 19.

Kalantzis, M, Cope, B \& Slade, D. (1989). Minority Languages and Dominant Culture. New York: Falmer Press.

Mishra, L. (2016). Focus Group Discussion in Qualitative Research. TechnoLEARN, 6(1) 1-5.

Mohajan, H.K. (2018). Qualitative Research Methodology in Social Sciences and Related Subjects. Journal of Economic Development, Environment and People, 7(1) 23-48.

Rahamah, N., Bakar, A. \& Abdullah, M.Y. (2008). The Life History Approach: Fieldwork Experience. Jurnal e-Bangi, 3(1) 1-9.

Sarantakos, S. (2013). Social Research. $4^{\text {th }}$ Edition. Hampshire: Palgrave Macmillan.

Shakouri, N. (2014). Qualitative Research: Incredulity toward Metanarrativeness. Journal of Education and Human Development, 3(2) 671-680.

Suryani, A. (2008). Comparing Case Study and Ethnography as Qualitative Research Approaches. Jurnal Ilmu Котиnikasi, 5(1) 117-128.

Yin, R.K. (2003). Applications of Case Study Research ( $2^{\text {nd }}$ Edition). London: SAGE Publications Ltd. 